\title{
Profiling of $\mathrm{CH}_{4}$ background mixing ratio in the lower troposphere with Raman lidar: a feasibility experiment
}

\author{
Igor Veselovskii ${ }^{1}$, Philippe Goloub ${ }^{2}$, Qiaoyun $\mathrm{Hu}^{2}$, Thierry Podvin ${ }^{2}$, David N. Whiteman ${ }^{3}$, Mikhael Korenskiy ${ }^{1}$, and \\ Eduardo Landulfo ${ }^{4}$ \\ ${ }^{1}$ Physics Instrumentation Center of General Physics Institute, Troitsk, Moscow, Russia \\ ${ }^{2}$ Laboratoire d'Optique Atmosphérie, Université de Lille-CNRS, Villeneuve-d'Ascq, France \\ ${ }^{3}$ NASA Goddard Space Flight Center, Greenbelt, USA \\ ${ }^{4}$ Instituto de Pesquisas Energeticas e Nucleares, São Paulo, Brazil
}

Correspondence: Igor Veselovskii (igorv@pic.troitsk.ru)

Received: 3 September 2018 - Discussion started: 20 September 2018

Revised: 7 December 2018 - Accepted: 12 December 2018 - Published: 7 January 2019

\begin{abstract}
We present the results of methane profiling in the lower troposphere using LILAS Raman lidar from the Lille University observatory platform (France). The lidar is based on a frequency-tripled Nd:YAG laser, and nighttime profiling up to 4000 with $100 \mathrm{~m}$ height resolution is possible for methane. Agreement between the measured photoncounting rate in the $\mathrm{CH}_{4}$ Raman channel in the free troposphere and numerical simulations for a typical $\mathrm{CH}_{4}$ background mixing ratio (2 ppm) confirms that $\mathrm{CH}_{4}$ Raman scattering is detected. The mixing ratio is calculated from the ratio of methane $(395.7 \mathrm{~nm})$ and nitrogen $(386.7 \mathrm{~nm}) \mathrm{Ra}-$ man backscatters, and within the planetary boundary layer, an increase of the $\mathrm{CH}_{4}$ mixing ratio, up to a factor of 2, is observed. Different possible interfering factors, such as leakage of the elastic signal and aerosol fluorescence, have been taken into consideration. Tests using backscattering from clouds confirmed that the filters in the Raman channel provide sufficient rejection of elastic scattering. The measured methane profiles do not correlate with aerosol backscattering, which corroborates the hypothesis that, in the planetary boundary layer, not aerosol fluorescence but $\mathrm{CH}_{4}$ is observed. However, the fluorescence contribution cannot be completely excluded and, for future measurements, we plan to install an additional control channel close to $393 \mathrm{~nm}$, where no strong Raman lines exist and only fluorescence can be observed.
\end{abstract}

\section{Introduction}

Raman spectroscopy is a powerful technique for identification of different gases in the atmosphere and for the estimation of their concentration (Weber, 1979), which can be used in conjunction with lidar technology (Inaba and Kobayasi, 1972). An example of such synergy is the Raman lidar for water vapor monitoring (Whiteman et al., 1992). For optimum application of the Raman technique, the gas of interest should be abundant in the atmosphere, possess a large scattering cross section and have a Raman spectrum that is isolated from potential interfering species. Detection of water vapor with Raman spectroscopy satisfies all of these conditions and has become a very popular application of lidar (e.g., Whiteman et al., 2007, and references therein). Besides water vapor, Raman lidar profiling of carbon dioxide (Ansmann et al., 1992; Whiteman et al., 2007; Zhao et al., 2008), as well as quartz crystals in dust layers (Müller et al., 2010), has been reported.

Methane is currently the second most important greenhouse gas (after carbon dioxide) of anthropogenic origin (IPCC, 2013). Methane is emitted from a variety of natural and anthropogenic sources (e.g., Baray et al., 2018; Kavitha et al., 2016, and references therein) and on a per-molecule basis, methane is about 30 times more effective a greenhouse gas than carbon dioxide (Etminan et al., 2016). Global information about the $\mathrm{CH}_{4}$ column concentration is available from satellite observations with, for example, the SCIAMACHY sensor on board the ENVISAT satellite (Bovensmann et al., 1999) or the TANSO-FTS sensor on board the 
GOSAT satellite (Kuze et al., 2009). Passive observations, however, can be influenced by the presence of aerosol layers or thin ice clouds. The lack of precise global measurements of atmospheric methane initiated, in particular, the upcoming MERLIN mission, offering integrated path differential absorption space-borne lidar (https://earth.esa.int/web/ eoportal/satellite-missions $/ \mathrm{m} / \mathrm{merlin}$, last access: 5 December 2018), which should provide unprecedented accuracy of $\mathrm{CH}_{4}$ column values. Still, the integrated path technique does not provide the profile of the methane mixing ratio, which can vary significantly in the lower troposphere.

Today, it is well established that, in the free troposphere the $\mathrm{CH}_{4}$ mixing ratio is about $2 \mathrm{ppm}$, while inside the planetary boundary layer (PBL), the mixing ratio can be increased in the vicinity of methane sources (Baray et al., 2018). Such enhancement up to $4 \mathrm{ppm}$ was observed, for example, in the airborne measurements over oil sands (Baray et al., 2018). At low altitudes, the methane concentration depends on the PBL dynamics, so it is important to profile the methane mixing ratio simultaneously with the PBL parameters such as PBL height and aerosol backscattering. Profiling of the PBL is commonly done by aerosol lidars (Kovalev and Eichinger, 2004), while for methane profiling either the differential absorption (DIAL) or Raman lidars can be used.

Existing DIAL systems for measuring methane are based on tunable parametric laser sources and operate in the shortwave infrared (SWIR) spectral range between 1.65 and $2.3 \mu \mathrm{m}$, where methane has strong absorption lines (Refaat et al., 2013; Riris et al., 2017). Due to low Raleigh scattering in the SWIR region, methane profiling using the DIAL technique is possible only inside regions containing significant amounts of aerosol. Raman lidars, by contrast, use standard off-the-shelf tripled Nd:YAG lasers, are relatively simple in design and can be operated in aerosol-free atmosphere. The methane molecule is quite suitable for Raman detection. The vibrational Raman line at $2914 \mathrm{~cm}^{-1}$ is well isolated and has the scattering cross section about 8 times higher than that of nitrogen (Weber, 1979). The main difficulties of $\mathrm{CH}_{4}$ Raman detection are related to its low background atmospheric concentration. The first attempts to implement $\mathrm{CH}_{4}$ Raman spectroscopy in lidars go back to the 1980s. Raman lidar was used for monitoring methane plumes with relative $\mathrm{CH}_{4}$ volume concentrations of about $2 \%$ (Houston et al., 1986). Monitoring of the background $\mathrm{CH}_{4}$ concentrations in the troposphere with airborne Raman lidar was reported by Heaps and Burris (1996). In both cases powerful excimer lasers (XeCl and $\mathrm{XeF}$ ) were used. However, the wideband radiation of excimer lasers requires the use of wideband interference filters in Raman channel, which, in turn, increases the sky background noise and possible contribution of aerosol fluorescence. Wideband detection also creates an additional complication related to interference from the oxygen Raman overtone (second Stokes shift) (Heaps and Burris, 1996). Significant progress in the development of the interference filters, detectors and laser sources during the last 2 decades now pro- vides the opportunity to develop the $\mathrm{CH}_{4}$ Raman lidar based on a relatively compact tripled Nd:YAG laser. For narrowband $354.7 \mathrm{~nm}$ laser radiation the vibrational Raman line of methane is at $395.7 \mathrm{~nm}$, while the oxygen Raman overtone $\left(3089 \mathrm{~cm}^{-1}\right)$ is at $398.4 \mathrm{~nm}$, which can be rejected by the interference filter.

In our paper we present the first results of methane profiling in the lower troposphere using LILAS Raman lidar from the Lille University observatory platform (Hauts-de-France region, France). The observations demonstrate that inside the $\mathrm{PBL}$, the $\mathrm{CH}_{4}$ mixing ratio may exceed the background concentration levels by up to a factor of 2. Enhancement of the $\mathrm{CH}_{4}$ mixing ratio in weak elevated aerosol layers was also detected.

\section{Experimental setup}

The experiments described here were performed using LILAS - multiwavelength Mie-Raman lidar from Lille University (Veselovskii et al., 2016). The lidar is based on a tripled Nd:YAG laser with a $20 \mathrm{~Hz}$ repetition rate and pulse energy of $70 \mathrm{~mJ}$ at $355 \mathrm{~nm}$. The backscattered light is collected by a $40 \mathrm{~cm}$ aperture Newtonian telescope. The outputs of the detectors are recorded at $7.5 \mathrm{~m}$ range resolution using Licel transient recorders that incorporate both analog and photon-counting electronics. The full geometrical overlap of the laser beam and the telescope field of view (FOV) is achieved at approximately $1000 \mathrm{~m}$ height using a $0.75 \mathrm{mrad}$ FOV. In its usual configuration, LILAS allows the detection of three elastic backscattered signals $(355,532,1064 \mathrm{~nm})$, a rotational Raman signal from $\mathrm{N}_{2}$ and $\mathrm{O}_{2}$ molecules at approximately $530 \mathrm{~nm}$ (Veselovskii et al., 2015), and vibrational nitrogen and water vapor Raman signals at 387 and $408 \mathrm{~nm}$. To take the $\mathrm{CH}_{4}$ measurements shown in this paper, we modified the water vapor channel $(408 \mathrm{~nm}$ interference filter was replaced by the methane filter centered at $395.7 \mathrm{~nm}$ ). The dichroic mirror in the receiver did not provide an efficient selection of the methane $(395.7 \mathrm{~nm})$ Raman component, so it was replaced by the mirror with high reflectance at $395.7 \mathrm{~nm}$. Only a small portion of the $387 \mathrm{~nm}$ component was transmitted to the nitrogen channel, while more than $95 \%$ of the $395.7 \mathrm{~nm}$ signal was reflected to the methane channel. Through comparing nitrogen Raman backscatter intensity before and after the modification we find that the sensitivity of the $387 \mathrm{~nm}$ channel was degraded by a factor of 185. The strength of the nitrogen Raman signal, though low, was sufficient for the purpose of our experiment.

The Alluxa interference filter in the methane Raman channel has a bandwidth of $0.3 \mathrm{~nm}$ with peak transmission greater than $80 \%$. The corresponding transmission curve, simulated by the manufacturer in the $300-550 \mathrm{~nm}$ range, is shown in Fig. 1. Suppression of 355 and $532 \mathrm{~nm}$ radiation is specified to be greater than 12 orders of magnitude. The Ramanscattering cross section of methane is about 8 times higher 


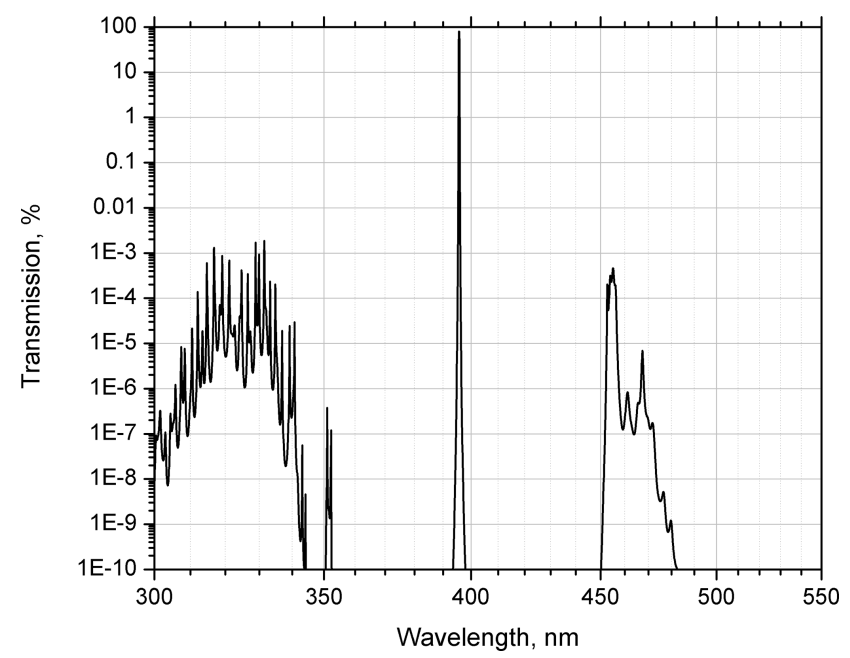

Figure 1. Simulated transmission curve of the methane filter provided by Alluxa.

than that of nitrogen, so for a $2 \mathrm{ppm}$ methane concentration the ratio of intensities of Raman nitrogen to methane scattering is about $6 \times 10^{4}$. Thus, not only should the elastic backscatter components of the signal be suppressed sufficiently, but so should the nitrogen and oxygen Stokes and anti-Stokes Raman lines. To eliminate the possible contribution of rotational anti-Stokes lines, the interference filter was combined with a notch filter, providing an additional OD4 blocking in the $348-360 \mathrm{~nm}$ range. The contribution of the vibrational anti-Stokes lines is the most significant for oxygen $(336.2 \mathrm{~nm})$, where the corresponding intensity is about 20 times the intensity of $\mathrm{CH}_{4}$ line. The filter suppression at $336.2 \mathrm{~nm}$ is about OD9, which is sufficient to block the antiStokes line contribution.

The intensity of the oxygen overtone $(398.4 \mathrm{~nm})$ is approximately 3 times the intensity of the methane line (Heaps and Burris, 1996), while the filter manufacturer specifies the suppression at $398.4 \mathrm{~nm}$ to be above OD10; hence the contribution of the oxygen overtone is negligible. To verify that no $532 \mathrm{~nm}$ backscatter or corresponding Raman lines leak into the methane channel, during the initial test phase a UV glass filter with transmission of less than $5 \%$ in the 500 $750 \mathrm{~nm}$ range was also added to the methane channel. No noticeable changes in $\mathrm{CH}_{4}$ Raman signals were discovered with this additional blocking filter in place. The transmission curve in Fig. 1 shows an increase in the $450-480 \mathrm{~nm}$ range, where aerosol fluorescence may occur (Sugimoto et al., 2012; Reichardt et al., 2017), with maximal transmission of $4 \times 10^{-4} \%$ at $455 \mathrm{~nm}$. The dichroic mirrors in the detection module provide additional suppression of factor 20 at this wavelength, so total suppression of fluorescence signal at $455 \mathrm{~nm}$ is greater than $4 \times 10^{6}$. All presented Raman methane measurements were taken in the photon-counting mode and at night only.
Table 1. Raman frequency shift for $\mathrm{H}_{2} \mathrm{O}, \mathrm{CO}_{2}$ and $\mathrm{CH}_{4}$ molecules and their scattering cross sections normalized to the cross section of nitrogen. Results are given for an excitation wavelength of $337 \mathrm{~nm}$ (Weber, 1979). Typical background-gas mixing ratios $n_{x}$ in the low troposphere and the product $n_{x} \times \frac{\sigma_{x}}{\sigma_{\mathrm{N}_{2}}}$ are also given.

\begin{tabular}{lrrrr}
\hline Molecule & $\begin{array}{r}\text { Frequency } \\
\left(\mathrm{cm}^{-1}\right)\end{array}$ & $\begin{array}{r}\frac{\sigma_{x}}{\sigma_{\mathrm{N}_{2}}} \\
\text { of } n_{x}(\mathrm{ppm})\end{array}$ & $\begin{array}{r}\text { Typical values } \\
(\mathrm{ppm})\end{array}$ \\
\hline $\mathrm{H}_{2} \mathrm{O}$ & 3657 & 3.1 & $3 \times 10^{3}$ & $\sim 10^{4}$ \\
$\mathrm{CO}_{2}$ & 1285 & 0.8 & 400 & 320 \\
$\mathrm{CH}_{4}$ & 2914 & 8.2 & 2 & 16.4 \\
\hline
\end{tabular}

\section{Numerical simulation}

Numerical simulation was performed to estimate the power of the Raman backscatter for the background methane mixing ratio. The lidar equation describing the number of detected photons $N_{x}^{\mathrm{ph}}$, scattered by molecule $x$ at distance $z$ due to a single laser pulse can be written as follows:

$$
\begin{aligned}
N_{x}^{\mathrm{ph}}(z) & =O(z) A_{x} \frac{E}{h v} \Delta z \frac{S}{z^{2}} N_{x} \sigma_{x} \\
& \exp \left\{-\int_{0}^{z}\left(\alpha_{\mathrm{L}}^{\mathrm{a}}+\alpha_{\mathrm{L}}^{\mathrm{m}}+\alpha_{x}^{\mathrm{a}}+\alpha_{x}^{\mathrm{m}}\right) \mathrm{d} z^{\prime}\right\} .
\end{aligned}
$$

Here $\mathrm{O}(\mathrm{z})$ is the geometrical overlap factor, $A_{x}$ is an efficiency factor, including the transmission of the optics and the quantum efficiency of the detectors. $E$ and $h v$ are the laser pulse and the photon energies, $\Delta z$ is range resolution, $S$ is the receiving telescope area, $N_{x}$ is the number concentration of molecule $x$ and $\sigma_{x}$ is the differential Ramanscattering cross section of molecule $x, \alpha$ is the extinction coefficient, where superscript "a" and " $m$ " indicate aerosol and molecular contributions. Subscript " $L$ " and " $x$ " correspond to the laser wavelength $\lambda_{L}$ and to the wavelength of Raman backscatter $\lambda_{x}$.

Table 1 shows the parameters of $\mathrm{H}_{2} \mathrm{O}, \mathrm{CO}_{2}$ and $\mathrm{CH}_{4}$ molecules, such as Raman frequency shift and Raman differential scattering cross section $\sigma_{x}$, normalized to the cross section of nitrogen $\sigma_{\mathrm{N}_{2}}$. Results are presented for an excitation wavelength of $337 \mathrm{~nm}$ based on Weber (1979). The table also provides typical concentrations of gases in the troposphere. The efficiency of detection of molecule $x$ is determined by the factor $n_{x} \times \frac{\sigma_{x}}{\sigma_{\mathrm{N}_{2}}}\left(n_{x}\right.$ is the molecule $x$ mixing ratio), which is approximately $10^{4}$ for the $\mathrm{H}_{2} \mathrm{O}$ molecule and about 320 for $\mathrm{CO}_{2}$. However, for $\mathrm{CH}_{4}$ this factor is about 20 times lower than for $\mathrm{CO}_{2}$, so detection of the methane background concentrations demands a powerful Raman lidar and significant signal accumulation time.

The lidar-derived mixing ratio of methane can be calculated from the ratio of $\mathrm{CH}_{4}$ and $\mathrm{N}_{2}$ lidar Raman signals $\left(P_{\mathrm{CH}_{4}}\right.$ and $P_{\mathrm{N}_{2}}$ ), corrected for the aerosol and molecular differential 
extinction:

$$
\begin{aligned}
n_{\mathrm{CH}_{4}}(z) & =K \frac{P_{\mathrm{CH}_{4}}}{P_{\mathrm{N}_{2}}} \exp \left\{-\int_{0}^{z}\left[\alpha_{\mathrm{N}_{2}}^{\mathrm{a}}\left(1-\left(\frac{\lambda_{\mathrm{CH}_{4}}}{\lambda_{\mathrm{N}_{2}}}\right)^{-\gamma}\right)\right.\right. \\
& \left.\left.+\alpha_{\mathrm{N}_{2}}^{\mathrm{m}}\left(1-\left(\frac{\lambda \mathrm{CH}_{4}}{\lambda_{\mathrm{N}_{2}}}\right)^{-4}\right)\right] \mathrm{d} z^{\prime}\right\} .
\end{aligned}
$$

Here $\lambda_{\mathrm{N}_{2}}$ and $\lambda_{\mathrm{CH}_{4}}$ are the wavelengths of nitrogen and methane Raman components; $\alpha_{N_{2}}^{\mathrm{a}}$ and $\alpha_{\mathrm{N}_{2}}^{\mathrm{m}}$ are the aerosol and molecular extinctions at $\lambda_{\mathrm{N}_{2}} ; \gamma$ is the Angstrom exponent and $K$ is the calibration constant. In our measurements, we assume that the $\mathrm{CH}_{4}$ mixing ratio above the boundary layer is 2 ppm and this value was used for calibration purposes. The calibration, in principle, can be performed from first principles by using a calibration lamp with a known spectrum, as has been done for Raman water vapor lidars (Venable et al., 2011). The methane mixing ratio in Eq. (2) is calculated from the ratio of the lidar signals, so the geometrical overlap factors are at least partially compensated and thus measurements below the height of the full overlap are possible. We still need to extrapolate the extinction coefficient to the region of incomplete overlap. However, the influence of the aerosol differential extinction term in Eq. (2) is lower than in the water vapor measurements due to the lower wavelength separation between nitrogen and methane Raman components.

To estimate the statistical uncertainties of methane detection, we assume that a uniform aerosol layer extends from the ground up to $2 \mathrm{~km}$ in height. In modeling the aerosol extinction coefficients at $355 \mathrm{~nm}$, extinction values of $0.05,0.1$ and $0.2 \mathrm{~km}^{-1}$ were considered. The number of detected photons was calculated from Eq. (1) for $\Delta z=100 \mathrm{~m}, A_{\mathrm{CH}_{4}}=0.1$ and $n_{\mathrm{CH}_{4}}=2 \mathrm{ppm}$. The assumed laser pulse energy was $70 \mathrm{~mJ}$ at $354.7 \mathrm{~nm}$, which corresponds with the LILAS laser energy during the observations reported. The nitrogen Ramanscattering cross section of $5.4 \times 10^{-31} \mathrm{~cm}^{2} \mathrm{sr}^{-1}$ at $488 \mathrm{~nm}$ is taken from Penney et al. (1974) and recalculated for $355 \mathrm{~nm}$. Finally, assuming that $\frac{\sigma_{\mathrm{CH}_{4}}}{\sigma_{\mathrm{N}_{2}}}=8.2$ (Weber, 1979), the value $\sigma_{\mathrm{CH}_{4}}=1.9 \times 10^{-29} \mathrm{~cm}^{2} \mathrm{sr}^{-1}$ at $355 \mathrm{~nm}$ was used. Statistical uncertainties of the measurements are determined mainly by the weak $\mathrm{CH}_{4}$ Raman backscatter and, in the absence of background noise, the uncertainty can be estimated as $\varepsilon \approx \frac{1}{\sqrt{N_{\mathrm{CH}_{4}}^{\mathrm{ph}}}}$.

Figure 2 shows vertical profiles of statistical uncertainties for three values of the aerosol extinction coefficient: 0.05 , $0.1,0.2 \mathrm{~km}^{-1}$ and a signal-averaging time of $4 \mathrm{~h}$. The figure also shows the photon-counting rate in the methane Raman channel $v_{\mathrm{CH}_{4}}=N_{\mathrm{CH}_{4}}^{\mathrm{ph}} \frac{2 \Delta z}{c}$, where $c$ is the speed of the light. For the clean atmosphere $\left(\alpha_{355}=0.05 \mathrm{~km}^{-1}\right)$ the measurements with uncertainty below $10 \%$ are possible up to $4 \mathrm{~km}$, while for $\alpha_{355}=0.2 \mathrm{~km}^{-1}$ the corresponding range decreases to $3 \mathrm{~km}$. The simulation results confirm the necessity

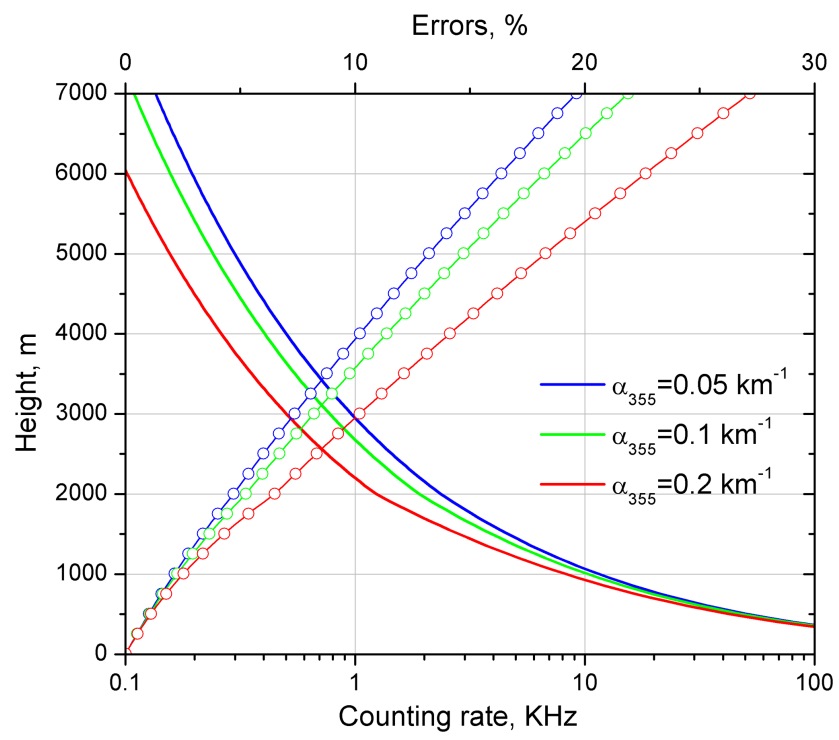

Figure 2. Modeled photon-counting rate (lines) and statistical uncertainties of the methane mixing ratio measurements (lines and symbols) for a $2 \mathrm{ppm}$ methane concentration and three values of aerosol extinction coefficient $\alpha_{355}=0.05,0.1,0.2 \mathrm{~km}^{-1}$. Aerosol extends from $z=0$ to $z=2000 \mathrm{~m}$. Signal-averaging time is $4 \mathrm{~h}$.

of long-term (several hours) signal accumulation in methane measurements using Raman lidar.

\section{Results of measurements}

Measurements were taken on the Lille University observatory platform, France, during the period May-June 2018. In total, 20 nighttime observation sessions were accomplished. Figure 3 shows $\mathrm{CH}_{4}$ and $\mathrm{N}_{2}$ Raman lidar signals together with the backscattered signal at $1064 \mathrm{~nm}$ on the night of 1415 June 2018. The results are averaged over the temporal interval $\tau_{\mathrm{av}}=4.0 \mathrm{~h}$. Aerosols are mainly located below $1700 \mathrm{~m}$ (maximal value of aerosol extinction $\alpha_{355}$ inside the PBL is about $0.1 \mathrm{~km}^{-1}$ ), though a weak aerosol layer is also visible in the $1064 \mathrm{~nm}$ lidar signal in the $2.5-4.0 \mathrm{~km}$ height interval. HYSPLIT back-trajectory analysis (Stein et al., 2015; Rolph et al., 2017) shows that the air mass in this layer originates from Canada, having been transported over the Atlantic. The photon-counting rate in the methane channel at $2000 \mathrm{~m}$ is about $1.8 \mathrm{KHz}$, which agrees with simulation results in Fig. 2 for $\alpha_{355}=0.1 \mathrm{~km}^{-1}$. As mentioned, for a $2 \mathrm{ppm} \mathrm{CH}_{4}$ mixing ratio, the nitrogen Raman backscatter should be approximately $6 \times 10^{4}$ stronger than that from methane. The value estimated from our measurements of $5 \times 10^{4}$ agrees well with this prediction, which confirms that we observed methane Raman scattering. The profile of the methane mixing ratio calculated from the measurements in Fig. 3 and averaged over $100 \mathrm{~m}$ height bins is shown in Fig. 4. The same figure provides the profile of the backscattering coefficient at 


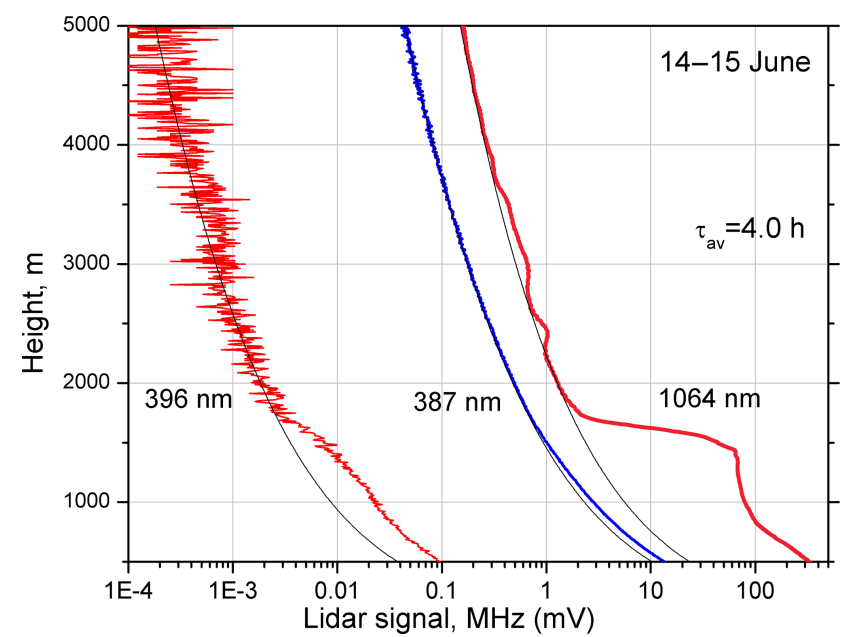

Figure 3. Lidar signals corresponding to elastic scattering at $1064 \mathrm{~nm}$, nitrogen Raman scattering at $387 \mathrm{~nm}$ and methane Raman scattering at $396 \mathrm{~nm}$ on the night of 14-15 June 2018. The units are $\mathrm{MHz}$ for 387 and $396 \mathrm{~nm}$, and $\mathrm{mV}$ for $1064 \mathrm{~nm}$. Black lines show the profiles of molecular scattering. Measurements were taken from 22:00 to 02:00 UTC. Signal-averaging time $t_{\text {aver }}=4.0 \mathrm{~h}$.

$532 \mathrm{~nm}$. The mixing ratio is given in arbitrary units, assuming that the value of 1.0 corresponds to $n_{\mathrm{CH}_{4}}=2 \mathrm{ppm}$. The mixing ratio inside the PBL exceeds the corresponding values above $4000 \mathrm{~m}$ by approximately a factor of 2 . The profiles of $n_{\mathrm{CH}_{4}}$ and $\beta_{532}$ are not correlated: inside the PBL the maximum of $\beta_{532}$ is at a height of $1500 \mathrm{~m}$, while the maximum of $n_{\mathrm{CH}_{4}}$ is at $1100 \mathrm{~m}$. The backscattering coefficient $\beta_{532}$ of the weak aerosol layer at $3500 \mathrm{~m}$ is about $7.6 \times 10^{-5} \mathrm{~km}^{-1} \mathrm{sr}^{-1}$, which is almost a factor of 50 lower than the maximum value of $\beta_{532}$ inside the PBL. In this elevated layer, the $\mathrm{CH}_{4}$ mixing ratio also increases; however $n_{\mathrm{CH}_{4}}$ at $3500 \mathrm{~m}$ is 1.5 , which is close to the values in the PBL. Thus, the enhancement of $n_{\mathrm{CH}_{4}}$ at $3500 \mathrm{~nm}$ is very unlikely to be an artifact related to aerosol interference.

The derived methane profiles exhibited strong night-tonight variation. Figure 5 shows the results of six measurement sessions, representing nights with different aerosol loadings. On the night of 20-21 May (Fig. 5a) a scattering layer with a peak value of $\beta_{532}=0.09 \mathrm{~km}^{-1} \mathrm{sr}^{-1}$ occurs in the $2500-3100 \mathrm{~m}$ height range. The low lidar ratio (below $20 \mathrm{sr}$ ) and low depolarization ratio (below $5 \%$ ) indicate that this layer is likely a water cloud. Strong cloud scattering demonstrates no influence on the mixing ratio, which is about 1.0 in the center of the cloud, proving that the interference filters provide sufficient rejection of elastic scattering. It should also be mentioned that the Raman band of the liquid water extends from 395 to $409 \mathrm{~nm}$ (Avila et al., 2004; Reichardt, 2014), so potentially it can be an interfering factor in the methane measurements. However, Fig. 5a does not reveal a noticeable effect of liquid water Raman scattering on the methane profile due to the narrowband fil-

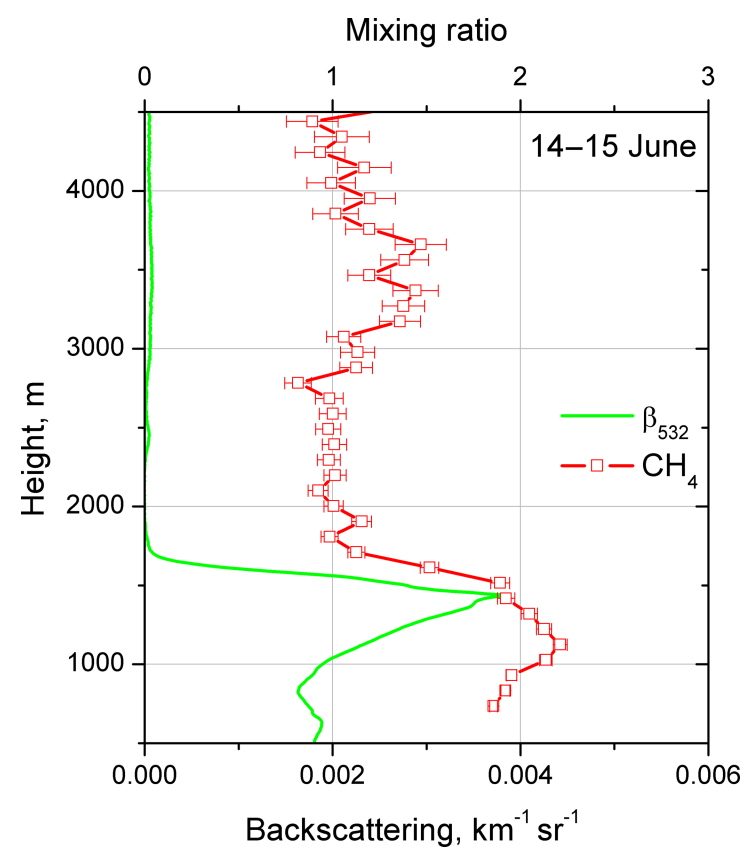

Figure 4. Vertical profiles of aerosol backscattering coefficient at $532 \mathrm{~nm}$ and methane mixing ratio calculated from measurements on 14-15 June for the same temporal interval as in Fig. 3. Mixing ratio is uncalibrated and the value 1.0 corresponds to approximately $2 \mathrm{ppm}$.

ter in the $\mathrm{CH}_{4}$ channel. Cloud layers also occurred on 2627 and 27-28 May (Fig. 5b, c) at a height of approximately $4000 \mathrm{~m}$ with maximum values of backscattering coefficients of $\beta_{532}=0.006$ and $0.02 \mathrm{~km}^{-1} \mathrm{sr}^{-1}$. As in Fig. 5a, the presence of clouds does not influence the methane measurements. By contrast, the night of 12-13 June (Fig. 5f) was characterized by a low aerosol backscattering coefficient in the $500-4000 \mathrm{~m}$ range $\left(\beta_{532}\right.$ is below $\left.2 \times 10^{-4} \mathrm{~km}^{-1} \mathrm{sr}^{-1}\right)$ and the mixing ratio shows no significant deviation from the 1.0 value in the whole height range.

The vertical variation of methane content was related to the PBL height, as can be concluded from a comparison of Fig. 5d and e. On 30-31 May the aerosol is confined below $2000 \mathrm{~m}$, while on 2-3 June it is below $750 \mathrm{~m}$. The $n_{\mathrm{CH}_{4}}$ decreases from 2.4 at $500 \mathrm{~m}$ to 1.0 at $2000 \mathrm{~m}$ in the first case, while in the second case the background level of 1.0 is observed for the heights above $750 \mathrm{~m}$. On 2-3 June, the increase of the $\mathrm{CH}_{4}$ mixing ratio at $3400 \mathrm{~m}$ correlates with a weak aerosol layer $\left(\beta_{532}<10^{-4} \mathrm{~km}^{-1} \mathrm{sr}^{-1}\right)$ at the same height. It is interesting that a stronger aerosol layer at $2300 \mathrm{~m}$ is not accompanied by an increase in $n_{\mathrm{CH}_{4}}$. The air masses in both layers were transported over the Atlantic from Canada and corresponding backward trajectories are close, so we are not able to make conclusions about the difference in the nature of these layers.

Enhancement of $n_{\mathrm{CH}_{4}}$ in weak elevated aerosol layers was observed several times during the campaign. In all cases the 

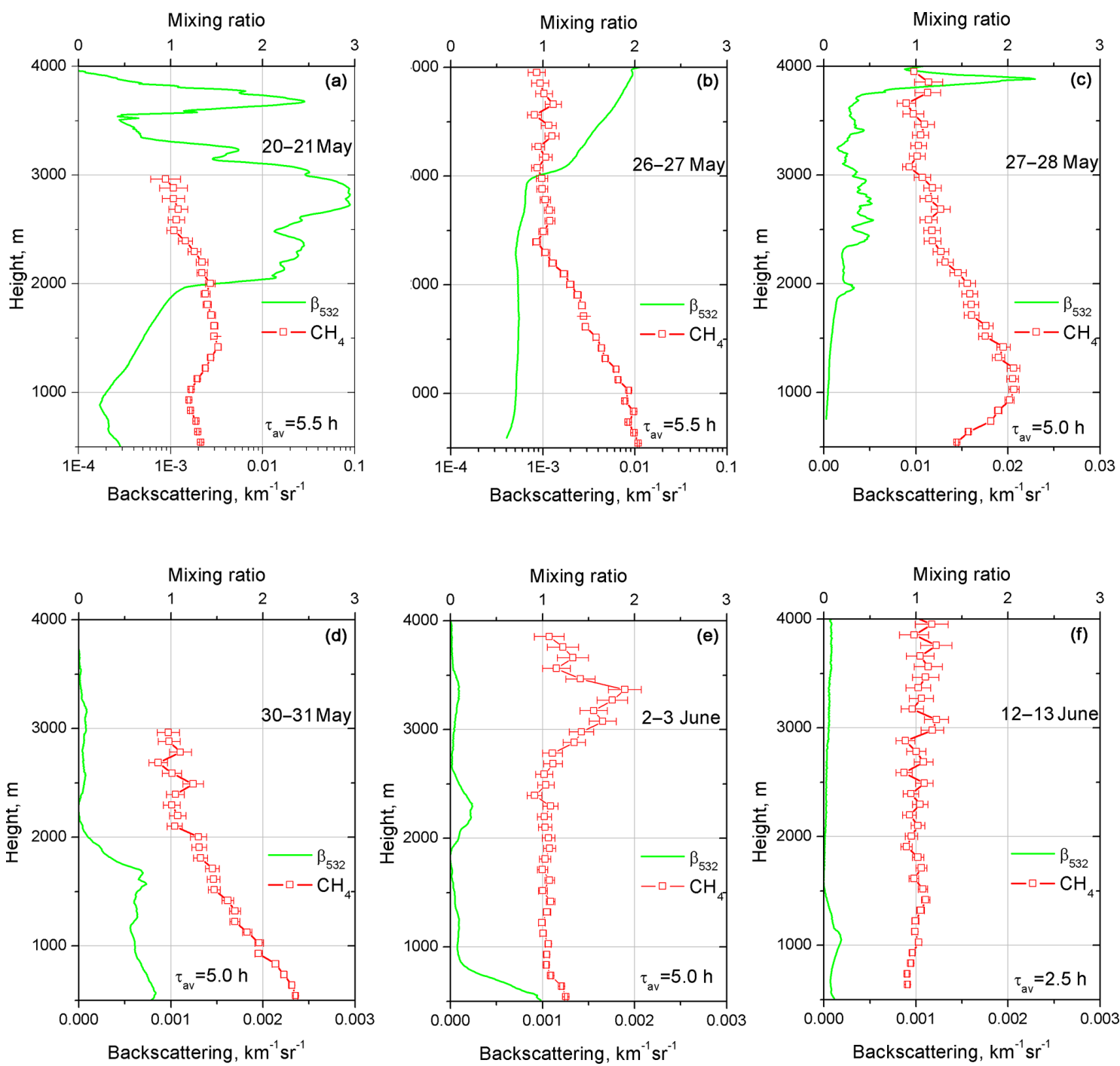

Figure 5. Vertical profiles of the methane mixing ratio and aerosol backscattering at $532 \mathrm{~nm}$ for six nighttime measurement sessions: (a) 2021 May, (b) 26-27 May, (c) 27-28 May, (d) 30-31 May, (e) 2-3 June and (f) 12-13 June 2018. Mixing ratios are not calibrated and the value 1.0 corresponds to approximately $2 \mathrm{ppm}$. Signal-averaging time $\tau_{\mathrm{av}}$ is given in hours.

air mass was transported over the Atlantic. One such observation session was on the night of 13-14 June 2018. Figure 6 shows the temporal-spatial distribution of the rangecorrected lidar signal at $1064 \mathrm{~nm}$ and the particle depolarization ratio at $532 \mathrm{~nm}$ for this session. Most of the aerosols are below $2000 \mathrm{~m}$, but there is an elevated layer in the 3000 $5000 \mathrm{~m}$ height range. The depolarization ratio inside the PBL is low $\left(\delta_{532}<5 \%\right)$, while in the elevated layer $\delta_{532}$ increases up to approximately $18 \%$. The available radiosonde data from Paris (France) and Essen (Belgium) show that the relative humidity in the elevated layer is below $40 \%$. The profiles of aerosol backscattering coefficient $\beta_{532}$, particle depolarization $\delta_{532}$ and $\mathrm{CH}_{4}$ mixing ratio on 13-14 June for the temporal interval of 22:00-02:00 UTC are given in Fig. 7. In the PBL the mixing ratio is about 2.0 , and in the elevated layer the $n_{\mathrm{CH}_{4}}$ also demonstrates an increase up to approximately 1.5 .

To understand the origin of this elevated layer, a 10-day back-trajectory analysis was performed for the air mass over Lille, at $4000 \mathrm{~m}$, on 14 June 2018 at 00:00 UTC, using the HYSPLIT model. According to the analysis, the air mass was transported from eastern Asia (Russia and China) to North America and then over the Atlantic Ocean to Europe. Large-scale boreal fire activities were detected near the border of Russia and China in early June; thus the air mass at $4000 \mathrm{~m}$ could have contained fire emissions. Figure $8 \mathrm{a}-\mathrm{d}$ plot the transport pathway of the air mass overlaid with the $\mathrm{CO}$ columnar concentration maps on 3, 6, 9 and 12 June. The $\mathrm{CO}$ concentration is derived from AIRS Level $3 \mathrm{CO}$ products (Texeira, 2013). The propagation of the air mass is clearly 

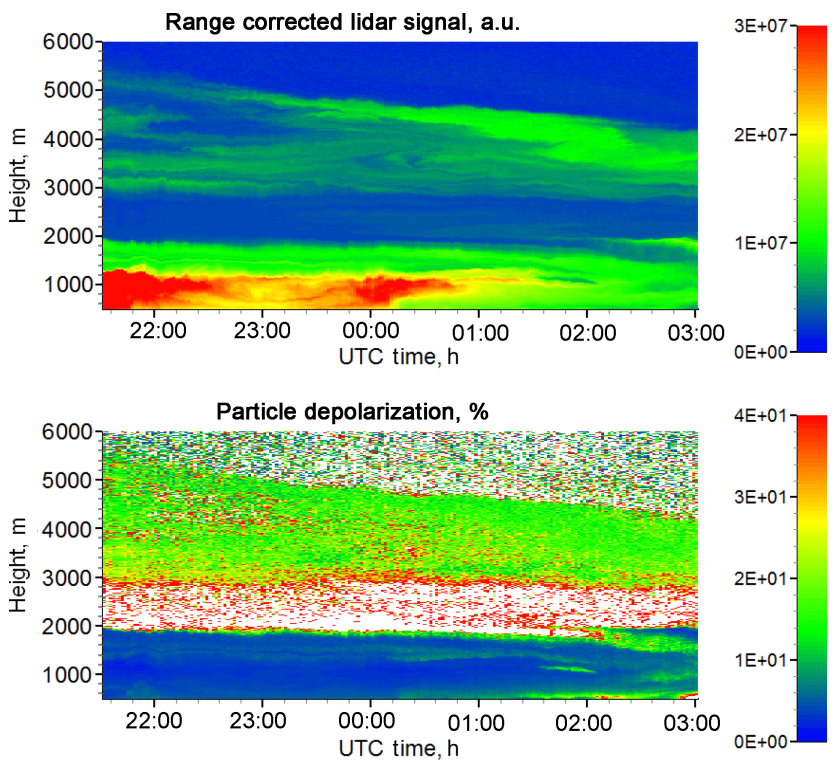

Figure 6. Range-corrected lidar signal at $1064 \mathrm{~nm}$ and the particle depolarization ratio at $532 \mathrm{~nm}$ for the night of 13-14 June 2018.

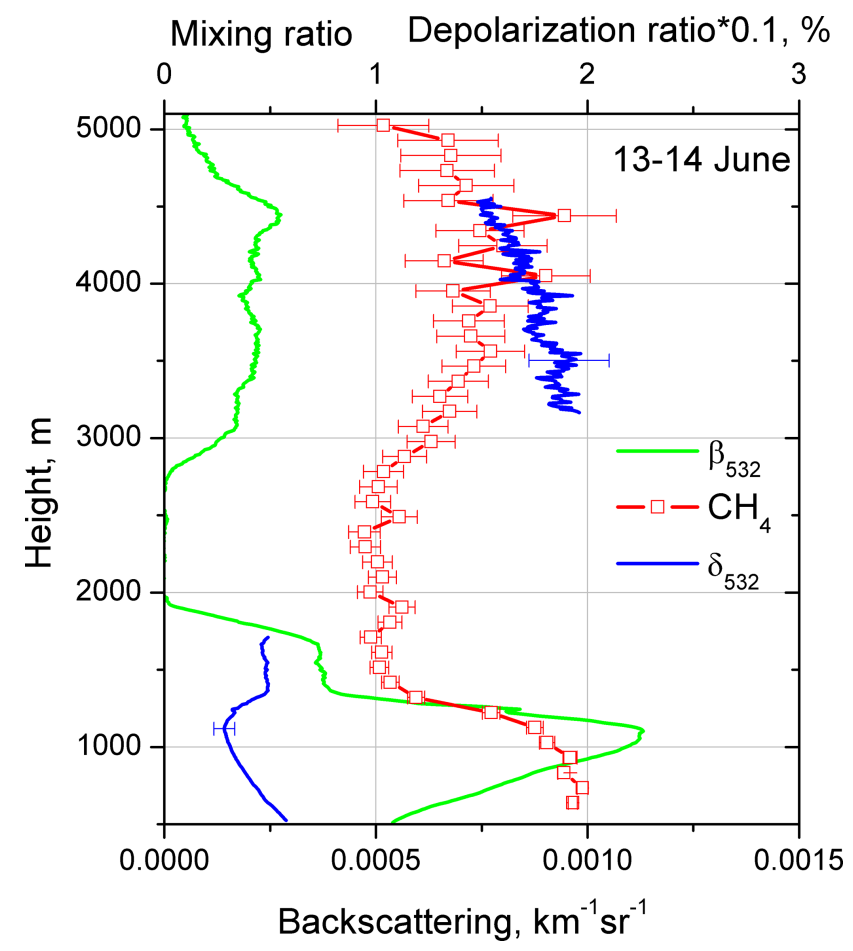

Figure 7. Aerosol backscattering coefficient $\beta_{532}$, particle depolarization $\delta_{532}$ and $\mathrm{CH}_{4}$ mixing ratio on 13-14 June 2018 for the temporal interval 22:00-02:00 UTC. Values of $\delta_{532}$ are multiplied by a factor of 0.1 . Mixing ratios are not calibrated and the value 1.0 corresponds to approximately $2 \mathrm{ppm}$.

coincident with the transport of $\mathrm{CO}$ plumes. Studies have shown that $\mathrm{CO}_{2}, \mathrm{CO}$ and $\mathrm{CH}_{4}$ are among the main products of boreal forest fires (Hao et al., 1993; Worden et al., 2013).
$\mathrm{CO}$ originating from boreal fires is positively correlated with $\mathrm{CH}_{4}$ concentration; however, the $\mathrm{CH}_{4}$ product of AIRS is not as mature as the $\mathrm{CO}$ product due to the low sensitivity to $\mathrm{CH}_{4}$ in the lower troposphere, so $\mathrm{CO}$ is a favorable tracer of fire emissions. In Fig. 8a, intense CO plumes are detected at the origin of the trajectory, which is close to the fire activities. Hence, it is possible that the observed methane plume comes from fire emissions in eastern Asia. Aged smoke particles mixed with Asian dust particles could be the reason for the high particle depolarization ratio observed in the elevated layer.

\section{Discussions and conclusion}

The results presented here demonstrate the feasibility of profiling the background mixing ratios of methane in the lower troposphere using Raman lidar. The photon-counting rate in the methane Raman channel agrees with numerical simulation for typical aerosol loading and a background $\mathrm{CH}_{4}$ mixing ratio of $2 \mathrm{ppm}$, which confirms that we observe the methane Raman scattering. In our measurements we always observed enhanced concentrations of the methane inside the PBL compared to aerosol-free regions; thus analysis of methane ground sources in northern France is in our upcoming plans.

Taking Raman measurements of $\mathrm{CH}_{4}$ mixing ratio close to $2 \mathrm{ppm}$ is a challenging task due to different potential interfering factors, such as leakage of the elastic signal into the Raman channel, contribution of liquid water Raman scattering and aerosol fluorescence. Measurements taken inside the clouds revealed no interference of elastic signal or Raman liquid water spectra. Estimation of aerosol fluorescence contributions is more difficult. The aerosol fluorescence at wavelengths above $440 \mathrm{~nm}$ was reported recently by Reichardt et al. (2017). For profiling, the authors had to integrate the fluorescence signal over the spectral range of approximately $80 \mathrm{~nm}$. In our system the filter bandwidth is only $0.3 \mathrm{~nm}$, so we expect the fluorescence contribution to be suppressed. The $\mathrm{CH}_{4}$ profiles are not always correlated with aerosol backscattering, which corroborates the hypothesis that, in the PBL, not aerosol fluorescence but methane is measured. However, we cannot completely exclude the fluorescence contribution. To measure and correct for it, if necessary, in future measurements we plan to introduce an additional control channel close to $393 \mathrm{~nm}$, where no strong Raman lines exist and only fluorescence can be detected (Reichardt, 2014). Furthermore, an additional filter will be used to increase the rejection in $450-480 \mathrm{~nm}$ spectral range.

One of the main problems in the measurements presented is the long signal accumulation time, which was about $4 \mathrm{~h}$ in our case. A more powerful laser is needed to improve the temporal resolution of the measurements. Today, compact diode pumped lasers, with pulse energies of $60 \mathrm{~mJ}$ at $355 \mathrm{~nm}$ and $200 \mathrm{~Hz}$ repetition rate have become widely avail- 
(a)

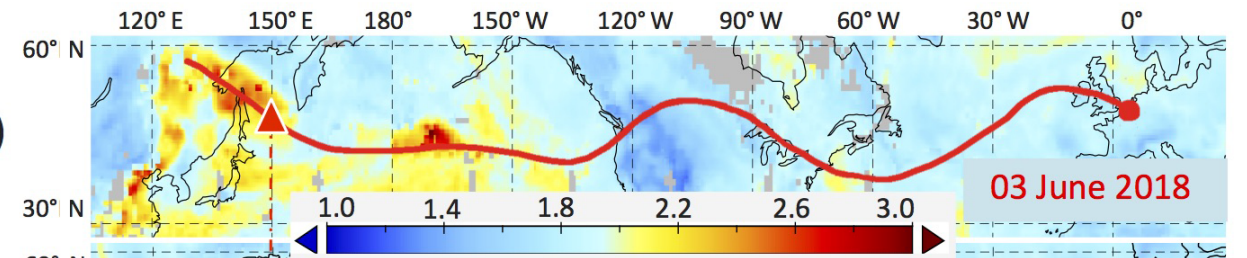

(b)

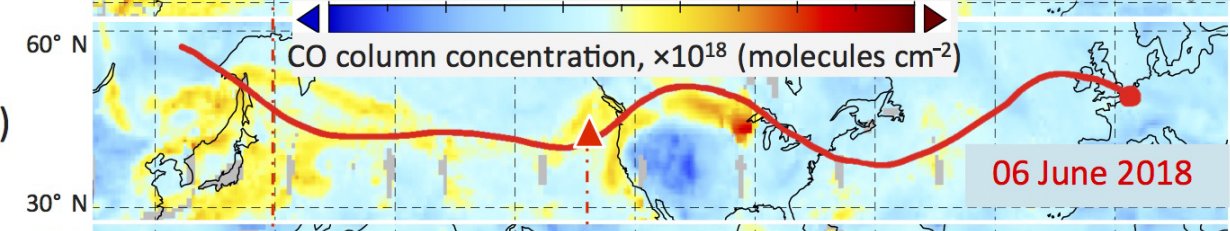

(c)

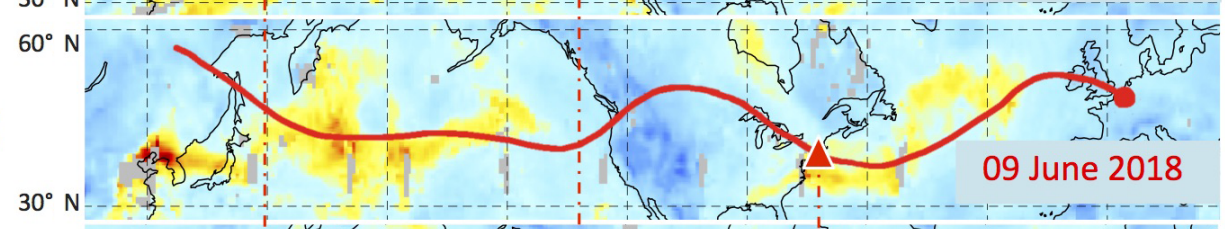

(d)

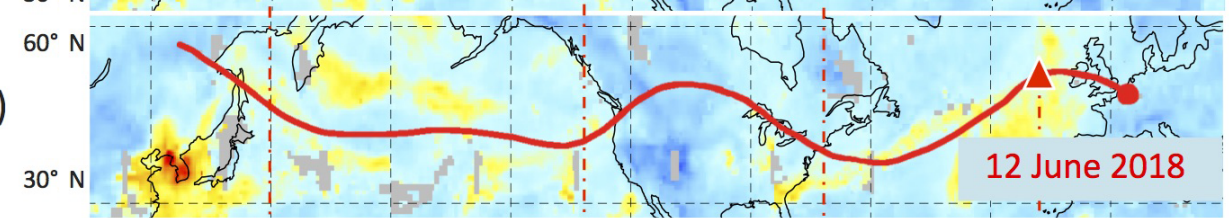

(e)

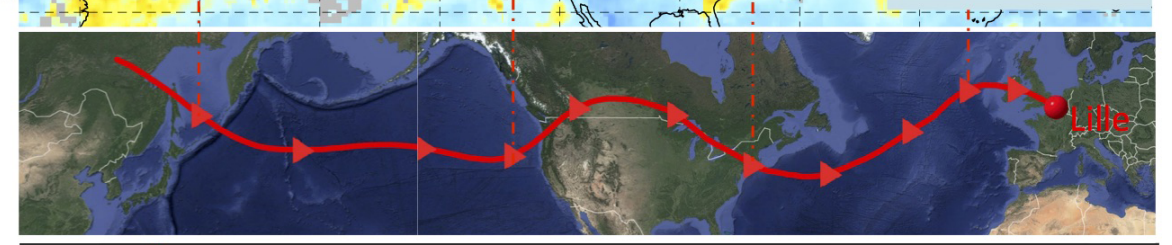

(f)

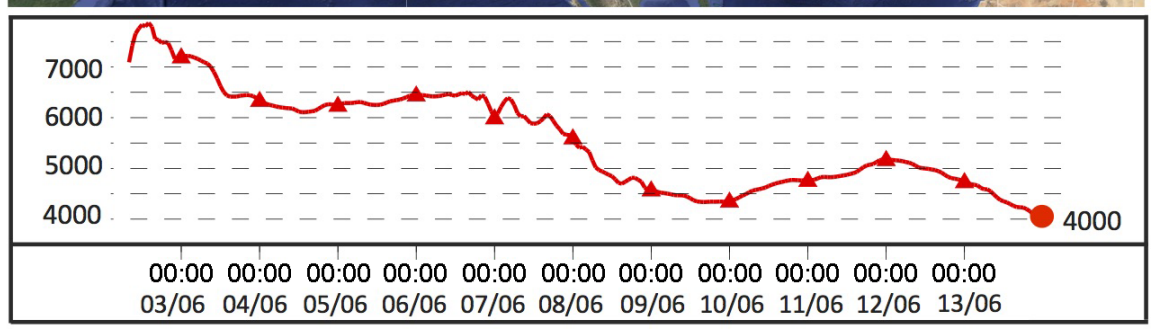

Figure 8. Ten-day backward trajectories for the air mass in Lille at an altitude of $4000 \mathrm{~m}$ on 14 June 2018 at 00:00 UTC. Panels (a)-(d) show the trajectory pathways overlaid with CO columnar concentration maps retrieved from AIRS data. The triangles represent the location of the traced air mass on corresponding dates. Panels (e) and (f) show the trajectory and vertical propagation of air mass.

able (e.g., http://www.quantel-laser.com/en/products/item/ q-smart-dpss-650-mj.html, last access: 20 December 2018), so it is possible to decrease the measurement time to less than 30 min. Numerous lidar technologies developed previously for $\mathrm{H}_{2} \mathrm{O}$ Raman systems can be used for the methane Raman lidar. In particular, the calibration technique based on the tungsten lamp spectrum can provide absolute values of methane mixing ratio from first principles (Venable et al., 2011).

Raman lidars for $\mathrm{CH}_{4}$ monitoring cannot, of course, compete with airborne DIAL systems in sensitivity and accuracy, especially when column concentrations are considered. However, when one needs to evaluate the vertical profile of methane concentrations through the boundary layer, the Raman lidar may have some advantages. In particular, the IR DIALs can profile methane only in the region loaded with aerosol, while Raman lidar is also capable of profiling in the aerosol-free atmosphere. Our results demonstrate that conventional Mie-Raman lidars designed for aerosol and the water vapor observations can be relatively easily modified for methane observations. Such ground-based lidars can be also used for ground validation activities during the upcoming MERLIN mission.

Data availability. Lidar measurements in Lille can be accessed under the following link: http://loa-ptfi.univ-lille1.fr/lidar/calendars/ cal_2018_lillelilas.php (last access: 3 January 2019)

Competing interests. The authors declare that they have no conflict of interest. 
Acknowledgements. The authors are very grateful to the labex CaPPA for supporting this study. The CaPPA project (Chemical and Physical Properties of the Atmosphere) is funded by the French National Research Agency (ANR) through the PIA (Programme d'Investissement d'Avenir) under contract "ANR-11-LABX-000501" and by the Regional Council "Nord-Pas de Calais" and the "European Funds for Regional Economic Development" (FEDER).

Edited by: Vassilis Amiridis

Reviewed by: Sergei Bobrovnikov and one anonymous referee

\section{References}

Ansmann, A., Riebesell, M., Wandinger, U., Weitkamp, C., Voss, E., Lahmann, W., and Michaelis, W.: Combined Raman elasticbackscatter lidar for vertical profiling of moisture, aerosols extinction, backscatter, and lidar ratio, Appl. Phys. B, 55, 18-28, 1992.

Avila, G., Fernidndez, J. M., Tejeda, G., and Montero, S.: The Raman spectra and cross-sections of H20, D20, and HDO in the OH/OD stretching regions, J. Mol. Spectr., 228, 38-65, 2004.

Baray, S., Darlington, A., Gordon, M., Hayden, K. L., Leithead, A., Li, S.-M., Liu, P. S. K., Mittermeier, R. L., Moussa, S. G., O'Brien, J., Staebler, R., Wolde, M., Worthy, D., and McLaren, R.: Quantification of methane sources in the Athabasca Oil Sands Region of Alberta by aircraft mass balance, Atmos. Chem. Phys., 18, 7361-7378, https://doi.org/10.5194/acp-187361-2018, 2018.

Bovensmann, H., Burrows, J. P., Buchwitz, M., Frerick, J., Noël, S., Rozanov, V. V., Chance, K. V., and Goede, A. H. P.: SCIAMACHY - Mission objectives and measurement modes, J. Atmos. Sci., 56, 127-150, 1999.

Etminan, M., Myhre, G., Highwood, E., and Shine, K.: Radiative forcing of carbon dioxide, methane, and nitrous oxide: A significant revision of the methane radiative forcing, Geophys. Res. Lett., 43, 12614-12623, https://doi.org/10.1002/2016GL071930, 2016.

Hao, W. M. and Ward, D. E.: Methane production from global biomass burning, J. Geophys. Res.-Atmos., 98, 20657-20661, 1993.

Heaps, W. S. and Burris, J.: Airborne Raman lidar, Appl. Opt., 35, 7128-7135, 1996.

Houston, J. D., Sizgoric, S., Ulitsky, A., and Banic, J.: Raman lidar system for methane gas concentration measurements, Appl. Opt., 25, 2115-2121, 1986.

Inaba, H. and Kobayasi, T.: Laser-Raman Radar - Laser-Raman scattering methods for remote detection and analysis of atmospheric pollution, Opto-Electronics, 4, 101-123, 1972.

IPCC: Climate Change 2013: The Physical Science Basis, Contribution of Working Group I to the Fifth Assessment Report of the Intergovernmental Panel on Climate Change, Cambridge University Press, Cambridge, United Kingdom and New York, NY, USA, 2013.

Kavitha, M. and Nair, P. R.: Non-homogeneous vertical distribution of methane over Indian region using surface, aircraft and satellite based data, Atmos. Environ., 141, 174-185, 2016.

Kovalev, V. A. and Eichinger, W. E.: Elastic lidar: theory, practice, and analysis methods, Wiley-Interscience, New York, 2004.
Kuze, A., Suto, H., Nakajima, M., and Hamazaki, T.: Thermal and near infrared sensor for carbon observation Fourier-transform spectrometer on the Greenhouse Gases Observing Satellite for greenhouse gases monitoring, Appl. Opt., 48, 6716-6733, 2009.

Müller, D., Mattis, I., Tatarov, B., Noh, Y. M., Shin, D. H., Shin, S. K., Lee, K. H., Kim, Y. J., and Sugimoto, N.: Mineral quartz concentration measurements of mixed mineral dust/urban haze pollution plumes over Korea with multiwavelength aerosol Raman-quartz lidar, Geophys. Res. Let., 37, L20810, https://doi.org/10.1029/2010GL044633, 2010.

Penney, C. M., Peters, R. L. S., and Lapp, M. : Absolute rotational Raman cross sections for $\mathrm{N}_{2}, \mathrm{O}_{2}$, and $\mathrm{CO}_{2}$, J. Opt. Soc. Am., 64, 712-716, 1974.

Reichardt, J.: Cloud and aerosol spectroscopy with Raman lidar, J. Atmos. Ocean. Tech., 31, 1946-1963, 2014.

Reichardt, J., Leinweber, R., and Schwebe, A.: Fluorescing aerosols and clouds: investigations of co-existance, Proceedings of the 28th ILRC, 25-30 June, Bucharest, Romania, 2017.

Refaat, T. F., Ismail, S., Nehrir, A. R., Hair, J. W., Crawford, J. H., Leifer, I., and Shuman, T.: Performance evaluation of a $1.6 \mu \mathrm{m}$ methane DIAL system from ground, aircraft and UAV platforms, Opt. Expr., 21, 30415-30432, 2013.

Riris, H., Numata, K., Wu, S., Gonzalez, B., Rodriguez, M., Scott, S., Kawa, S., and Mao, J.: Methane optical density measurements with an integrated path differential absorption lidar from an airborne platform, J. Appl. Remote Sens., 11, 034001-034019, 2017.

Rolph, G., Stein, A., and Stunder, B.: Real-time Environmental Applications and Display system: READY, Environ. Modell. Soft., 95, 210-228, 2017.

Stein, A. F., Draxler, R. R, Rolph, G. D., Stunder, B. J. B., Cohen, M. D., and Ngan, F.: NOAA's HYSPLIT atmospheric transport and dispersion modeling system, B. Am. Meteorol. Soc., 96, 2059-2077, 2015.

Sugimoto, N., Huang, Z., Nishizawa, T., Matsui, I., and Tatarov, B.: Fluorescence from atmospheric aerosols observed with a multichannel lidar spectrometer, Opt. Expr., 20, 20800-20807, 2012.

Texeira, A. S. T.: AIRS/Aqua L3 Daily Standard Physical Retrieval (AIRS-only) $1^{\circ} \times 1^{\circ}$ V006, Greenbelt, MD, USA, Goddard Earth Sciences Data and Information Services Center (GES DISC), https://doi.org/10.5067/Aqua/AIRS/DATA303, 2013.

Venable, D. D., Whiteman, D. N., Calhoun, M. N., Dirisu, A. O., Connell, R. M., and Landulfo, E.: Lamp mapping technique for independent determination of the water vapor mixing ratio calibration factor for a Raman lidar system, Appl. Opt., 50, 46224632, 2011.

Veselovskii, I., Whiteman, D. N., Korenskiy, M., Suvorina, A., and Pérez-Ramírez, D.: Use of rotational Raman measurements in multiwavelength aerosol lidar for evaluation of particle backscattering and extinction, Atmos. Meas. Tech., 8, 41114122, https://doi.org/10.5194/amt-8-4111-2015, 2015.

Veselovskii, I., Goloub, P., Podvin, T., Bovchaliuk, V., Derimian, Y., Augustin, P., Fourmentin, M., Tanre, D., Korenskiy, M., Whiteman, D. N., Diallo, A., Ndiaye, T., Kolgotin, A., and Dubovik, O.: Retrieval of optical and physical properties of African dust from multiwavelength Raman lidar measurements during the SHADOW campaign in Senegal, Atmos. Chem. Phys., 16, 70137028, https://doi.org/10.5194/acp-16-7013-2016, 2016. 
Weber, A.: Raman spectroscopy of gases and liquids, Springer, New York, 1979.

Whiteman, D. N., Melfi, S. H., and Ferrare, R. A.: Raman Lidar System for Measurement of Water Vapor and Aerosols in the Earth's Atmosphere, Appl. Opt., 31, 3068-3082, 1992.

Whiteman, D. N., Veselovskii, I., Cadirola, M., Rush, K., Comer, J., Potter, J. R., and Tola, R.: Demonstrations measurements of water vapor, cirrus clouds, and carbon dioxide using a highperformance Raman lidar, J. Atmos. Ocean. Tech. 24, 1377$1388,2007$.
Worden, J., Wecht, K., Frankenberg, C., Alvarado, M., Bowman, K., Kort, E., Kulawik, S., Lee, M., Payne, V., and Worden, $\mathrm{H}$.: $\mathrm{CH}_{4}$ and $\mathrm{CO}$ distributions over tropical fires during October 2006 as observed by the Aura TES satellite instrument and modeled by GEOS-Chem, Atmos. Chem. Phys., 13, 3679-3692, https://doi.org/10.5194/acp-13-3679-2013, 2013.

Zhao, P., Zhang, Y., Wang, L., Cao, K., Su, J., Hu, S., and Hu, H.: Measurement of tropospheric $\mathrm{CO}_{2}$ and aerosol extinction profiles with Raman lidar, Chinese Opt. Lett., 6, 157-160, 2008. 